\title{
PENGARUH ABU SEKAM PADI SEBAGAI BAHAN PENGISI UNTUK PEMBUATAN TUNGKU RUMAH TANGGA
}

\section{EFECT OF RICE HUSK ASH AS FILLER FOR A FURNACE OF HOUSEHOLD}

\author{
Alexius Luther Ola \\ Balai Riset dan Standardisasi Indsutri Manado \\ Jalan Diponegoro No. 21-23 \\ Pos-el : ola.luther@yahoo.co.id \\ Diterima Tanggal 07-5-2014, Disetujui Tanggal 21-5-2015
}

\begin{abstract}
ABSTRAK
Penelitian Abu sekam padi sebagai bahan pengisi dalam pembuatan tungku rumah tangga telah dilakukan, melalui tahap penelitian bahan baku dan aplikasi pembuatan tungku.Penelitian ini bertujuan untuk mendapatkan komposit bahan baku untuk bodi/badan tungku yang sesuai dan mendapatkan hasil desain tungku yang sesuai untuk keperluan rumah tangga. Hasil pengamatan dan uji fisik komposit bahan diperoleh susut kering rata-rata antara kisaran 5,24-9,49\%, susut bakar dengan kisaran 0,80-1,82\%, kuat tekan 46,66-70,84 kg/cm² dan dalam keadaan baik, tidak retak, tidak bengkok pada pengeringan dan pembakaran 700 ${ }^{\circ} \mathrm{C}$.Selanjutnya dibuat tungku dengan komposit bahan dari Abu Sekam Padi (ASP) 1 bagian dengan 3 bagian Tanah Liat Plastis (TLP) dan 2 bagian ASP +3 bagian TLP dengan model 2 lubang dan 4 lubang aliran udara pada badan tungku. Hasil uji coba penggunaan tungku memasak air $500 \mathrm{ml}$ diperoleh waktu tercepat adalah 11,65 menit dengan bahan bakar $665 \mathrm{~g}$ pada $\left(X_{2} Y_{1}\right)$. Hasil pengamatan suhu dalam ruang bakar setelah pemakaian tungku selama 210 menit menunjukkan suhu tertinggi $60^{\circ} \mathrm{C}$ pada tungku dengan perlakuan bahan 1 bagian ASP + 3 bagian TLP dengan model tungku 2 lobang (X2Y1) dan terendah $40{ }^{\circ} \mathrm{C}$ pada tungku perlakuan bahan tanpa ASP dengan model 2 lobang (XOY1) dan perlakuan bahan tanpa abu sekam dengan model tungku 4 lobang (X0Y2).
\end{abstract}

Kata kunci: Abu, Sekam Padi, Tungku Rumah Tangga.

\section{ABSTRACT}

The study of the effect of rice husk ash as a filler in making of household furnace has been carried out which includes raw material analysis and then furnace making. This study aims to obtain composite materials for the furnace's body and to create a design that is suitable for domestic use. The observation and physical testing of composite materials showed drying shrinkage of 5.24-9.49\%, burning shrinkage of $0.80-1.82 \%$, compressive strength of 46.66 $70.84 \mathrm{~kg} / \mathrm{cm}^{2}$, producing good-shaped product with no crack, no bent on draining at sunshines and burning at $700{ }^{\circ} \mathrm{C}$. Based on this information, furnaces were made with a composite material made from: (a) 1 part of rice husk ash (ASP) and 3 parts of flexible clay (TLP), and (b) 2 parts of $A S P+3$ parts of TLP. Furnace of each treatment is designed to have 2 holes and 4 holes for air flow. The result showed that the fastest time for boiling of $500 \mathrm{ml}$ of water using 665 $g$ of wood was 11.65 minutes. Observation of the highest temperature in the combustion chamber when the furnace has been used for 210 minutes was $60^{\circ} \mathrm{C}$ in treatment (a) with 2 holes; while the lowest temperature was $40{ }^{\circ} \mathrm{C}$ in treatment without TLP with 2 holes and in treatment without ASP with 4 holes.

Keywords: ash, household furnaces, rice husk.

\section{PENDAHULUAN}

Sekam padi (Rice husk/rice hull) atau kulit gabah adalah bagian terluar dari butir padi dan memiliki kandungan silika terbanyak dibandingkan dengan hasil samping pengolahan padi lainnya.Hasil samping dari pengolahan padi antara lain jerami $(4,0-7,0) \%$; bekatul $(0,6-1,1) \%$, 
$\operatorname{dedak}(0,2-0,3) \%$ dan sekam $(18,0-22,3) \%$ (1).

Secara umum penggunaan sekam di Indonesia masih terbatas yaitu sebagai media tanaman hias, pembakaran bata merah, alas ternak untuk unggas, kuda, sapi, kambing, dan kerbau. Di Indonesia dan Filipina, sekam padi juga dipakai dalam penetesan telur itik. Sebagai pupuk, sekam padi mempunyai nilai rendah karena kadar NPK-nya yang rendah. Tetapi penambahan abu sekam atau sekam kedalam lahan memberikan pengaruh positif, terutama dalam penyerapan silika (2).

Sekam dikategorikan sebagai biomasa yang dapat digunakan untuk berbagai kebutuhan seperti bahan baku industri, pakan ternak dan energi atau bahan bakar ataupun sebagai adsorbsi pada logam-logam berat. Sekam tersusun dari jaringan-jaringan serat-serat selulosa yang mengandung banyak silica dengan bentuk serabut-serabut yang sangat keras. Pada keadaan normal, sekam berperan penting melindungi biji beras dari kerusakan yang disebabkan oleh serangan jamur, dapat mencegah reaksi ketengikan karena dapat melindungi lapisan tipis yang kaya minyak terhadap kerusakan mekanisme selama pemanenan, penggilingan dan pengangkutan (3).

Ditinjau dari komposisi kimianya, sekam padi mengandung beberapa unsur penting seperti kadar air $(32,40-41,35) \%$, Serat (31,37-49,92)\%, Abu (13,1629,04)\%, Pentosa (16,94-21,95)\%, Selulosa $(34,34-43,80) \%$ dan Liguin $(21,40-46,97) \%$. [2,5]. Sedangkan kandungan kimia dari abu hasil pembakaran sekam padi yang tertinggi adalah Silikat (SiO2) yakni 86,90-97,30\%, yang lain seperti Kalium, Natrium, Calsium, Magnesium, besi dan lain-lain terdapat dalam jumlah yang lebih kecil (4).

Sekam padi sulit untuk dinyalakan dan tidak mudah terbakar dengan api diruang terbuka, kecuali udara ditiupkan kedalamnya. Sekam padi sangat tahan terhadap kelembaban dan pertumbuhan jamur yang menyebabkan sekam padi sulit untuk terurai secara alami (5).

Sekam padi memiliki masa jenis yang rendah yaitu $70-110 \mathrm{Kg} / \mathrm{m}^{3}$ dalam bentuk briket atau pellet. Dengan demikian untuk penyimpanan dan transportasi, sekam padi membutuhkan volume besar, yang membuat transportasi jarak jauh menjadi tidak ekonomis. Ketika sekam padi dibakar, kadar abu yang diperoleh adalah 17-26\%, jauh lebih tinggi dari pada bahan bakar lainnya (kayu 0,2-2\%, batu bara $12,2 \%)$. Sekam padi memiliki nilai kalori rata-rata dari $3410 \mathrm{kkal} / \mathrm{kg}$ dan dapat digunakan sebagai salah satu sumber energi terbarukan (6).

Dalam pembakaran sekam padi akan menghasilkan $20 \%$ abu dengan komponen utamanya Silika (SiO2). Silika dalam abu terdapat dalam bentuk kristal dan pembakaran pada suhu $800-900{ }^{\circ} \mathrm{C}$ dalam bentuk amorfphous. Silika dalam bentuk amorphous sangat penting karena sangat reaktif.Pada pembakaran secara terbuka dapat menghasilkan abu dengan silika dalam bentuk amorphous $85-90 \%$ dan 10-15\% adalah carbon (7).

Mengingat jumlah sekam ini sangat banyak dan merupakan limbah di daerah persawahan, maka diupayakan pemanfaatannya sebagai bahan pengisi 
dalam pembuatan tungku rumah tangga untuk masyarakat pedesaan maupun perkotaan berbahan bakar kayu.

Dalam pembuatan tungku rumah tangga ini bahan dasarnya adalah tanah liat yang ditambahkan dengan bahan abu sekam padi, atau sekam padi yang telah dibakar. Abu sekam padi yang sifatnya tidak plastis (silikat Amorfh), jika dicampur dengan tanah liat plastis secara homogen dapat dibentuk menjadi suatu benda, memiliki kekuatan kering dan setelah dibakar pada suhu tertentu (8).

Di daerah Sonder Kabupaten Minahasa terdapat satu unit usaha yang membuat dan memasarkan tungku yakni tungku yang dibuat dengan campuran abu sekam dan tanah liat, dikeringkan lalu dicat merah, namun produksinya masih sedikit dan pemasarannya baru disekitar masyarakat setempat.

Pengusaha pembuat tungku abu sekam ini menyatakan bahwa penggunaan abu sekam dalam pembuatan tungku, karena tungku ini lebih panas dan atau lebih bertahan panasnya. Pembuatan tungku sejenis di Desa Pulutan Kabupaten Minahasa tidak menggunakan abu sekam padi tetapi setelah pengeringan dibakar hingga matang (sama dengan hasil pembakaran bata merah). Desain atau model tungku dari kedua daerah tersebut sama yakni hanya satu lubang/pintu bagian depan untuk mengeluarkan hasil sisa pembakaran dan atau untuk memasukkan bahan bakar kayu.

Permasalahan lainnya dari tungku rumah tangga abu sekam adalah pada penggunaan tungku yaitu lamanya waktu pemasakan sehingga pengguna harus menunggu lama untuk mendapatkan hasil masakan dan untuk menyalakan api agak lama serta berasap yang disebabkan oleh kurangnya lubang saluran udara pada badan tungku. Jadi lamanya waktu pemasakan dikarenakan tidak berpusatnya api yang dihasilkan dan banyaknya kalori yang diserap oleh material konstruksi tungku.

Penelitian ini mencoba memecahkan permasalahan yang ada dengan merancang suatu tungku rumah tangga dari abu sekam padi yang pada penggunaanya memiliki api yang berpusat dan badan tungku yang kuat/mampu menerima beban, awet dalam perjalanan atau transport. Indikator keberhasilan pengoperasian adalah semakin minimnya lama pemasakan.

Penelitian ini bertujuan untuk mendapatkan komposisi bahan baku dalam penggunaan abu sekam padi sebagai bahan pengisi dan mendesain tungku yang sederhana, waktu yang diperlukan dalam penggunaannya untuk memasak lebih singkat serta sampai berapa besarnya panas yang tersimpan dalam tungku dengan waktu tertentu.

\section{BAHAN DAN METODE}

\section{Bahan dan Alat}

Bahan-bahan yang digunakan dalam penelitian ini adalah tanah liat plastis, abu sekam padi, kayu bakar, loyang plastik, ember, gayung, sarung tangan, masker, karung plastic, ayakan kawat kassa, serbet, minyak tanah dan multiplex.

Peralatan yang digunakan adalah timbangan, sigmat, gergaji, thermometer, 
stop watch, tatanan, rak pengering, mall cetakan dan alat uji laboratorium.

\section{Metode Penelitian}

Penelitian dilakukan melalui 2 tahap dan pada tahap I dilaksanakan untuk mendapatkan gambaran kekuatan komposisi bahan dari penggunaan bahan abu sekam padi dalam pembuatan tungku rumah tangga.

Variasi campuran bahan Abu Sekam Padi (ASP) dengan tanah liat plastis (TLP) sebagai berikut :

Tabel 1. Variasi campuran bahan baku

\begin{tabular}{ccc}
\hline $\begin{array}{c}\text { Kode } \\
\text { Contoh }\end{array}$ & $\begin{array}{c}\text { Abu Sekam Padi } \\
\text { ASP }(\%)\end{array}$ & $\begin{array}{c}\text { Tanah Liat Plastis } \\
\text { TLP }(\%)\end{array}$ \\
\hline A1 & 10 & 90 \\
A2 & 20 & 80 \\
A3 & 30 & 70 \\
A4 & 40 & 60 \\
A5 & 50 & 50 \\
A6 & 60 & 40 \\
A0 & 0 & 100 \\
\hline
\end{tabular}

Keterangan :

A1 - A5 = komposisi bahan penelitian

A6 = komposisi bahan dari Sonder

$\mathrm{A} 0=$ komposisi bahan dari pulutan

Campuran bahan (adonan ASP + TLP) sesuai perlakuan masing-masing dicetak dalam bentuk bata kecil dengan ukuran (2x5x12) $\mathrm{cm}$ sebanyak 6 buah, dengan ulangan 2 kali. Bata percobaan selanjutnya dikeringkan dan diukur susut keringnya, kemudian dibakar pada suhu $\pm 700{ }^{\circ} \mathrm{C}$ lalu diukur susut bakarnya dan selanjutnya diuji kekuatan fisiknya.

\section{Penelitian Tahap II}

Pada penelitian tahap dua ini dibuat tungku dengan komposisi campuran bahan :

\footnotetext{
$\mathrm{X0}=$ Tanah Liat (TL) tampa penambahan Abu

\section{Tahapan Pembuatan Tungku Rumah Tangga}

Tanah liat plastis dari penggalian dikeringkan pada sinar matahari, digiling kemudian diayak dengan ayakan mesh No.10 atau ayakan kawat kassa diameter $\pm 2 \mathrm{~mm}$. Abu sekam padi dari pembakaran sekam padi secara terbuka, diayak dengan ayakan mesh No.10 atau atau kawat kassa diameter $\pm 2 \mathrm{~mm}$.

Dibuat mall cetakan dari multiplex dan kayu dengan bentuk model tungku yang ada di masyarakat yaitu dalam bentuk kubus..

Bahan ASP dan TLP diukur atau ditimbang masing-masing sesuai perlakuan yang telah ditentukan, kemudian kedua bahan dicampur hingga merata, ditambahkan air sedikit demi sedikit sambil diaduk dengan meremas-remas hingga campuran bahan 
homogen dalam keadaan pasta. Adonan bahan dimasukan kedalam mall cetakan sedikit demi sedikit sambil ditekan-tekan hingga seluruh ruang dalam cetakan terisi. Biarkan bahan cetakan dalam mall selama \pm 1 (satu) minggu untuk pemadatan dan pengeluaran air pembentuk yang berlebihan. Setelah barang cukup kering dan kuat, mall dilepaskan dan barang cetakan dibiarkan lagi beberapa hari agar lebih kering dan kuat. Selanjutnya dilakukan finishing dan pembentukan lubang pada bidang sisi yang dikehendaki dan dibiarkan lagi beberapa hari hingga lebih kering. Barang cetakan yang sudah kering dibakar pada temperatur $\pm 700{ }^{\circ} \mathrm{C}$ untuk mencapai kekuatan maksimal

Setelah pembakaran selesai, barang tetap dibiarkan dalam tempat pembakaran selama $\pm 1 \times 24$ jam untuk pendinginan Barang hasil pembakaran yakni Tungku
Rumah Tangga dari Abu Sekam Padi siap untuk digunakan.

\section{Pengamatan dan pengujian di lakukan terhadap:}

Pengamatan dan pengujian dilakukan terhadap benda coba komposisi bahan baku seperti keadaan dan susut kering, keadaan dan susut bakar serta uji fisik kuat tekan. Pengamatan terhadap waktu yang diperlukan dan berapa banyak bahan bakar yang digunakan serta suhu dalam ruang tungku diukur setelah tungku selesai digunakan. Pengukuran dilakukan setiap 10 menit (berkala) selama 120 menit, kemudian pengamatan 3 kali dengan interval 30 menit.

\section{HASIL DAN PEMBAHASAN}

Hasil pengamatan, pengukuran dan pengujian terhadap benda coba komposit bahan baku pembuatan tungku rumah tangga dapat dilihat pada Tabel 2.

Tabel 2. Hasil pengamatan dan pengujian komposisi bahan pembuatan tungku :

\begin{tabular}{|c|c|c|c|c|c|}
\hline $\begin{array}{l}\text { Kode } \\
\text { contoh }\end{array}$ & $\begin{array}{l}\text { Keadaan } \\
\text { kering }\end{array}$ & $\begin{array}{l}\text { Susut } \\
\text { kering (\%) }\end{array}$ & $\begin{array}{l}\text { Susut } \\
\text { bakar (\%) }\end{array}$ & keadaan & $\begin{array}{l}\text { kuat tekan } \\
\text { (Kg/cm }\end{array}$ \\
\hline $\bar{A} 1$ & $\begin{array}{l}\text { Tdk beng } \\
\text { kok, tidak } \\
\text { retak }\end{array}$ & 9,49 & 1,79 & $\begin{array}{l}\text { agak re- } \\
\text { tak, agak } \\
\text { bengkok }\end{array}$ & 70,84 \\
\hline $\mathrm{A} 2$ & $\begin{array}{l}\text { Tdk beng- } \\
\text { kok, tidak } \\
\text { retak }\end{array}$ & 8,71 & 0,98 & $\begin{array}{l}\text { tdk retak, } \\
\text { tdk beng- } \\
\text { kok. }\end{array}$ & 66,99 \\
\hline A3 & $\begin{array}{l}\text { Tdk beng- } \\
\text { kok, tidak } \\
\text { retak }\end{array}$ & 7,1 & 0,78 & $\begin{array}{l}\text { tdk retak, } \\
\text { tdk beng- } \\
\text { kok. }\end{array}$ & 58,3 \\
\hline A4 & $\begin{array}{l}\text { Tdk beng- } \\
\text { kok, tidak } \\
\text { retak }\end{array}$ & 6,12 & 0,78 & $\begin{array}{l}\text { tdk retak, } \\
\text { tdk beng- } \\
\text { kok. }\end{array}$ & 53,33 \\
\hline A5 & $\begin{array}{l}\text { Tdk beng- } \\
\text { kok, tidak } \\
\text { retak }\end{array}$ & 5,24 & 0,8 & $\begin{array}{l}\text { tdk retak, } \\
\text { tdk beng- } \\
\text { kok. }\end{array}$ & 46,66 \\
\hline A6 & $\begin{array}{l}\text { Tdk beng- } \\
\text { kok, tidak } \\
\text { retak }\end{array}$ & 3,68 & 0,49 & $\begin{array}{l}\text { agak re- } \\
\text { tak, tdk } \\
\text { bengkok }\end{array}$ & 31,3 \\
\hline $\mathrm{AO}$ & $\begin{array}{l}\text { Tdk beng- } \\
\text { kok, tidak } \\
\text { retak }\end{array}$ & 9,7 & 2,46 & $\begin{array}{l}\text { tdk retak, } \\
\text { agak beng } \\
\text { kok. }\end{array}$ & 77,5 \\
\hline
\end{tabular}

Keterangan :

A1-A5 = Komposit Bahan ASP dan TLP

A6 = Komposit Bahan Tungku Dari Pengusaha di Sonder

A0 $\quad$ Bahan Tanah Liat dari Pulutan 
Kekuatan bahan setelah dikeringkan diperlukan agar produk hasil cetakan mampu menahan beban waktu dipindahkan dan ketika disusun dalam tungku untuk pembakaran tidak mengalami cacat yang berarti. Hasil pengamatan terhadap komposit bahan baku untuk pembuatan badan tungku dalam keadaan kering (Tabel. 2) menunjukkan bahwa benda uji (A1-A5) tidak berubah, tidak bengkok dan tidak retak, demikian halnya untuk kode A6 ( komposit bahan dari Sonder ). Untuk kode A0 (komposit bahan dari Polutan) sedikit mengalami retak. Hasil pengamatan dan pengukuran susut kering terdapat pada kisaran $5.24-9.49 \%$ dan yang tertinggi terdapat pada komposit bahan $\mathrm{A} 0=9.70 \%$. Susut kering ini menunjukkan bahwa semakin banyak penambahan abu sekam padi semakin kecil susut keringnya. Tanah liat bersifat plastis memberikan susut kering yang tinggi dan oleh sebab itu diperlukan air pembentuk lebih besar. Air pembenuk ini akan hilang secara bertahap saat produk mengalami penyusutan dan sekaligus memberikan kekuatan kering pada produk tersebut (9).

Dari semua benda coba (A1-A5 termasuk A6) prosentase susut keringnya memenuhi syarat, karena tidak lebih dari $10 \%$ (Tabel 2).

Hasil pengamatan benda coba setelah pembakaran pada temperatur sampai $\pm 700{ }^{\circ} \mathrm{C}$ (Tabel 2) menunjukan bahwa semua benda coba (A1-A5) tetap baik seperti pada saat kering udara yaitu tidak retak dan tidak mengalami perubahan bentuk seperti melengkung atau bengkok. Dan hasil uji susut bakar (Tabel 2) menunjukan bahwa susut bakar terkecil $0,80 \%$ (A5) dan tertinggi 1,82\% (A1). Hal ini berarti semua benda coba (A1-A5) susut bakarnya memenuhi syarat atau tidak lebih dari 3 (tiga) persen. Susut bakar ini merupakan pengurangan panjang suatu benda coba dari keadaan kering udara setelah mengalami pembakaran pada suhu yang ditentukan. Dimana bahan-bahan untuk benda-benda keramik yang sudah kering mengalami susut kembali setelah dibakar dan susut bakar ini tidak boleh terlalu besar ( $\max 3 \%$ ) agar tidak menimbulkan perubahan bentuk seperti cacat, pecah dan retak (10).

Dari hasil uji kuat tekan (Tabel 5) diketahui bahwa rata-rata kuat tekan tertinggi terdapat pada komposit bahan $90 \%$ TLP + 10\% ASP (A1) yakni 70,84 $\mathrm{kg} / \mathrm{cm}^{2}$ sedangkan kuat tekan terendah pada komposit bahan $50 \%$ TLP + 50\% ASP (A5) yakni rata rata $46,66 \mathrm{~kg} / \mathrm{cm}^{2}$. Dibandingkan dengan komposit bahan yang digunakan oleh pengusaha tungku sekam di daerah Sonder ternyata menunjukan kuat tekan lebih rendah yakni $31,30 \mathrm{~kg} / \mathrm{cm}^{2}$. Hal ini berarti dalam komposit bahan tersebut abu sekam padi lebih banyak dari pada tanah liat plastis yang digunakan sebagai bahan tungku. Kuat tekan dari bahan untuk bodi/badan tungku memberikan gambaran tentang kemampuan produk atau barang menahan beban yang diberikan. Hasil analisis menunjukan bahwa dengan perlakuan penambahan atau penggunaan abu sekam padi yang lebih besar dari semua perlakuan mengalami penurunan kuat tekan. Hal ini desebabkan oleh karena ketidak 
seimbangan antara bahan pengikat atau perekat dengan volume bahan yang tidak memiliki daya ikat seperti abu sekam.

Dengan memperhatikan hasil pengamatan dan uji fisik bata percobaan pada penelitian pendahuluan tersebut diatas, maka penggunaan abu sekam padi dalam pembuatan tungku sebaiknya maksimal $40 \%$ dari total komposisi bahan yang digunakan. Hal ini memungkinkan tungku dalam penggunaannya masih mampu menahan beban sampai seberat 50 $\mathrm{kg}$.

\section{Desain tungku rumah tangga hasil penelitian dapat dilihat pada Gambar 1 dan Gambar 2.}

Desain tungku rumah tangga dari abu sekam padi dibuat dalam 2 model aliran udara, yakni $Y 1=2$ lubang (depanbelakang) dan Y2=4 lubang (depanbelakang dan kiri-kanan), dari variasi campuran badan tungku $\mathrm{X} 1=\left(\begin{array}{ll}1 & \mathrm{ASP}+3\end{array}\right.$ TLP) dan $\mathrm{X} 2=(2 \mathrm{ASP}+3 \mathrm{TLP})$. Gambar 1 desain tungku dua lubang dengan komposisi bahan X1 dan X2 ditambah kontrol ( tungku tanpa abu sekam ).

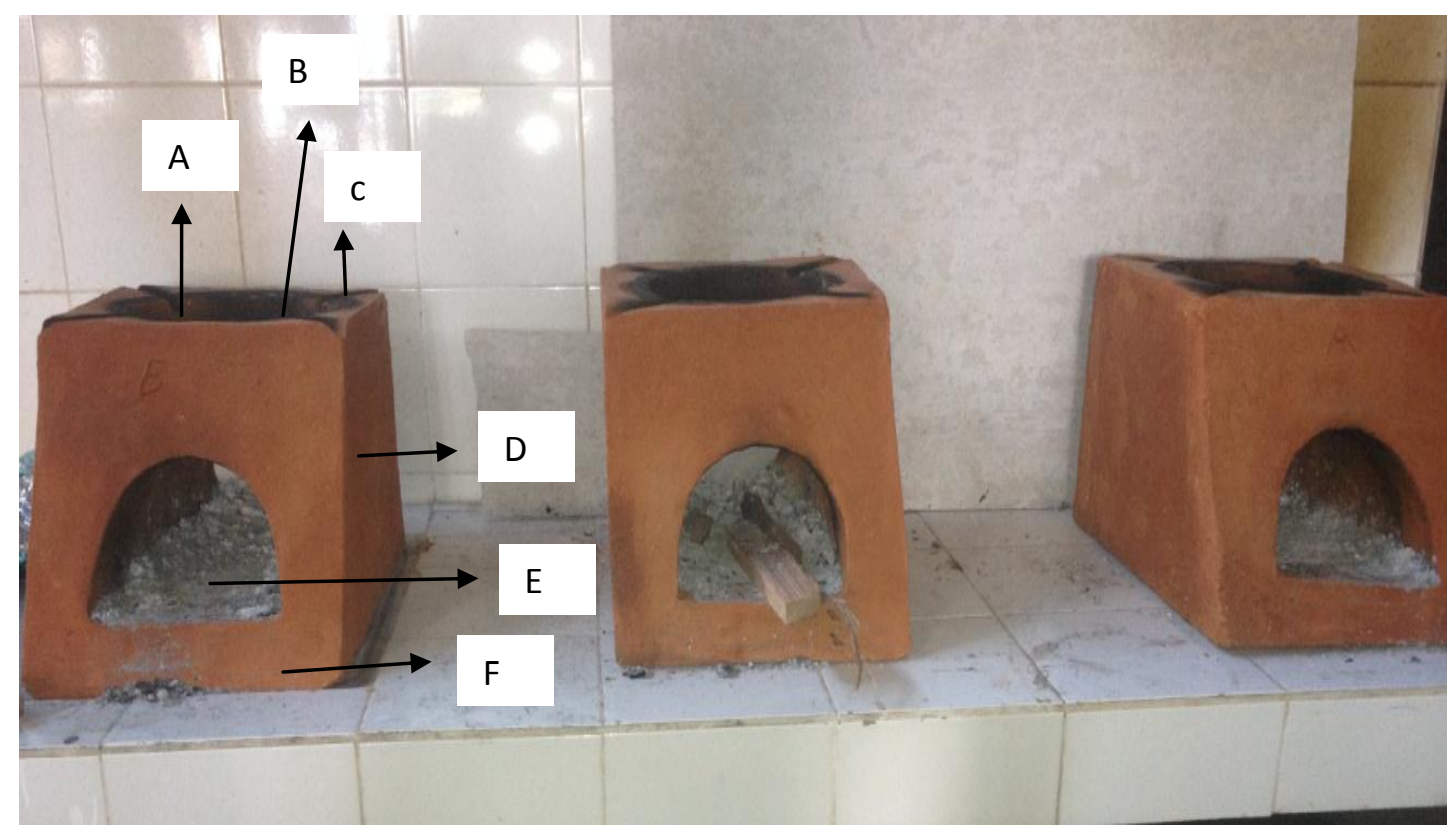

Gambar 1. Model Tungku RT Abu Sekam 2 Lubang

Keterangan :

A = Diameter lubang dudukan wajan $(\varnothing 19)$

$\mathrm{B}=$ Diameter lubang angin belakang (Ø12)

$\mathrm{C}=$ Tinggi badan tungku $(27 \mathrm{~cm})$

$\mathrm{D}=$ Panjang tungku $(40,5 \mathrm{~cm})$

$\mathrm{E}=$ Pintu masuk bahan bakar kayu (tinggi $13,5 \mathrm{~cm}$ dan lebar $16,5 \mathrm{~cm}$ )

$\mathrm{F}=$ Lebar badan tungku $(27 \mathrm{~cm})$ 


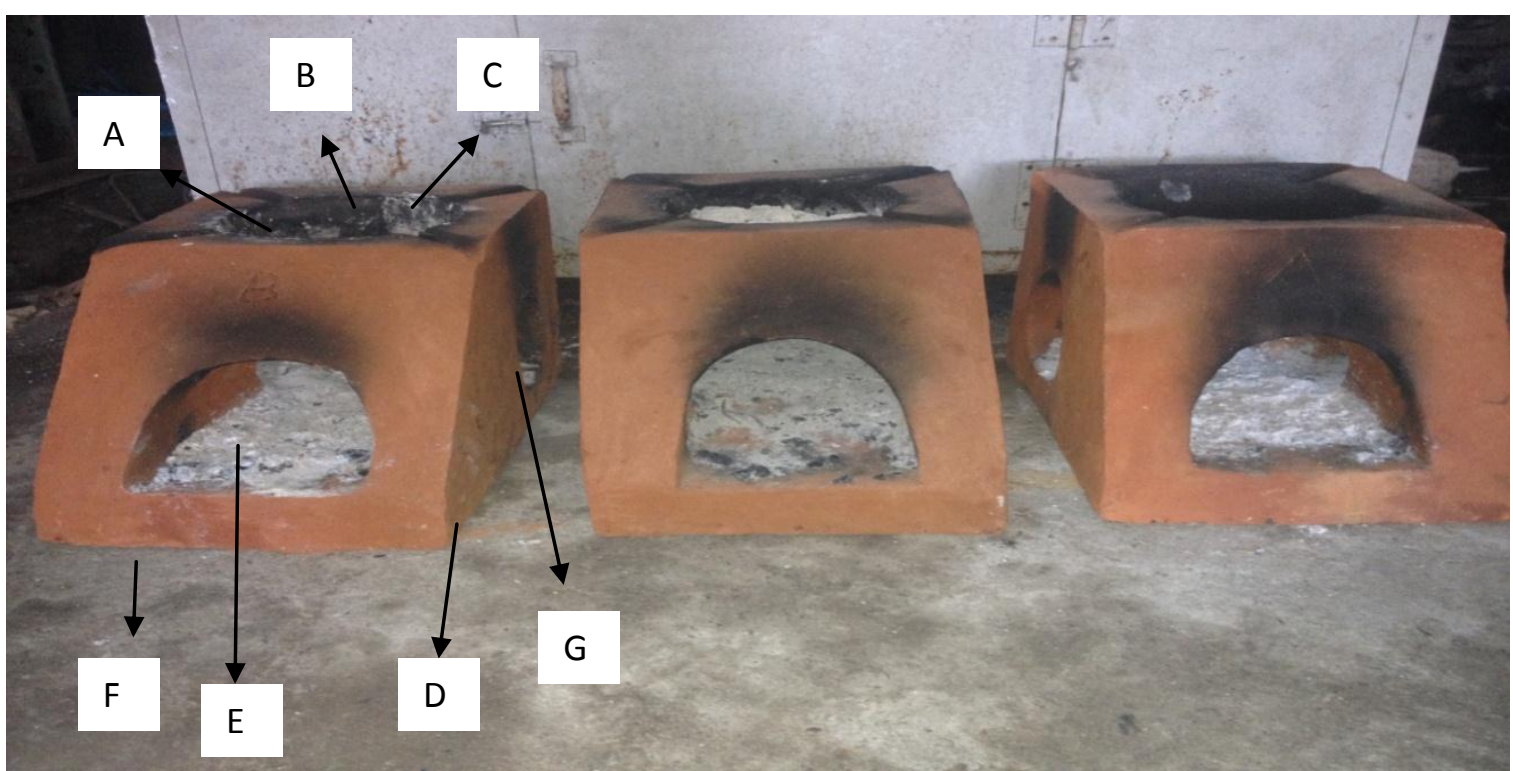

Gambar 2. Model Tungku RT Abu Sekam 4 Lubang

Keterangan :

A = Diameter lubang dudukan wajan $(\varnothing 19)$

$\mathrm{B}=$ Diameter lubang angin belakang $(\varnothing 12)$

$\mathrm{C}=$ Tinggi badan tungku $(27 \mathrm{~cm})$

$\mathrm{D}=$ Panjang tungku $(40,5 \mathrm{~cm})$

$\mathrm{E}=$ Pintu masuk bahan bakar kayu (tinggi $13,5 \mathrm{~cm}$ dan lebar $16,5 \mathrm{~cm}$ )

$\mathrm{F}=$ Lebar badan tungku $(27 \mathrm{~cm})$

$\mathrm{G}=$ Diameter Lubang angin samping kiri dan kanan ( $\varnothing 11)$

Untuk mengetahui waktu penggunaan dan besarnya suhu/panas yang tertinggal dalam tungku dengan bahan pengisi abu sekam padi, maka dilakukan uji coba penggunaan tungku dengan memasak air sejumlah $3 \times 5$ liter menggunakan kayu bakar.

Lamanya waktu pemasakan dan jumlah penggunaan bahan bakar dapat dilihat dalam Tabel 3 dibawah ini.

Tabel 3. Hasil pengamatan waktu dan bahan bakar memasak air $5000 \mathrm{ml}$

\begin{tabular}{ccc}
\hline Kode & $\begin{array}{c}\text { Kayu bakar } \\
\text { (gram) }\end{array}$ & $\begin{array}{c}\text { Waktu } \\
\text { (menit) }\end{array}$ \\
\hline XOY1 & 735 & 21,66 \\
XOY2 & 1035 & 30,69 \\
X1Y1 & 710 & 12,07 \\
X1Y2 & 835 & 26,68 \\
X2Y1 & 665 & 11,65 \\
X2Y2 & 867 & 26,67 \\
\hline
\end{tabular}

Dari hasil pengamatan pada Tabel 3. dapat dilihat bahwa untuk mendidihkan air sebanyak 5 liter diperlukan waktu seperti pada kisaran 11.65-30,69 menit dengan 
penggunaan kayu bakar sebesar pada kisaran 665-1035 gram.

Penggunaan waktu tercepat ( 11.65 menit ) terdapat pada tungku dengan komposit bahan 2 bagian ASP +3 bagian TLP dengan model 2 lubang dan pemakaian kayu bakar sejumlah 665 gram (X2Y1). Sedangkan penggunaan waktu terlama ( 30,69 menit ) terdapat pada tungku dengan model 4 lubang dengan komposit bahan tanpa ASP (XOY2).

Dari hasil pengamatan tersebut dapat diketahui adanya perbedaan yang nyata dalam penggunaan tungku baik dari segi lamanya waktu pemasakan dan jumlah pemakaian bahan bakar. Model tungku dengan 2 lubang (Y1) dengan pemakaian abu sekam padi lebih banyak, memerlukan waktu pemasakan yang lebi cepat dan penggunaan bahan bakar lebih sedikit. Menurut Belonio (10) pembakaran merupakan suatu proses kimia yang terjadi karena kombinasi yang cepat antara oksigen dan elemen kimia yang menghasilkan panas. Hasil uji coba menggunakan tungku dengan memasak

Air sebanyak 5 liter, pada penggunaan tungku 2 lubang jumlah udara lebih banyak terperangkap dalam ruang tungku sehingga kebutuhan panas/energy dibandingkan dengan tungku 4 lubang. Hal ini tentunya disebabkan panas atau energi yang dibutuhkan lebih banyak keluar pada tungku 4 lubang(Y2) sehingga pada hakekatnya dibutuhkan bahan bakar lebih banyak.

\section{Suhu Dalam Ruang Tungku}

Pengukuran suhu dalam ruang tungku dilakukan setelah tungku selesai digunakan dalam uji coba memasak air. Pengukuran dilakukan setiap 10 menit sepanjang 120 menit kemudian dilanjutkan pengamatan dan pengukuran 3 kali 30 menit (90 menit) (Tabel 4).

Hasil pengukuran suhu ruang tungku rumah tangga dari abu sekam padi (Tabel 4), dapat diketahui bahwa terjadi penurunan suhu secara bertahap pada semua perlakuan. Laju penurunan suhu lebih cepat terjadi pada tungku dengan model 4 lubang dan tungku kontrol (tidak menggunakan abu sekam).

Pada pengukuran sampai 120 menit tungku rumah tangga dengan 2 lubang perlakuan (X1Y1), suhu dalam ruang tungku adalah sebesar $70{ }^{\circ} \mathrm{C}$. Sedangkan tungku rumah tangga dengan model 4 lubang pada perlakuan (X1Y2), suhu dalam ruang tungku adalah sebesar $60{ }^{\circ} \mathrm{C}$ dan pada perlakuan (X2Y1), suhu dalm ruang tungku adalah sebesar $80{ }^{\circ} \mathrm{C}$. Dan perlakuan (X2Y2) suhu sebesar $65^{\circ} \mathrm{C}$. Dibandingkan dengan suhu kontrol (tanpa abu sekam padi) untuk 2 lubang (XOY1) suhu dalam ruang tungku $45{ }^{\circ} \mathrm{C}$ dan pada model 4 lubang (XOY2) suhu dalam ruang tungku 40 ${ }^{\circ} \mathrm{C}$. 
Tabel 4. Hasil pengukuran suhu pada ruang tungku rumah tangga abu sekam

\begin{tabular}{cccccccc}
\hline \multirow{2}{*}{ No } & Waktu & \multicolumn{6}{c}{ Suhu ${ }^{\circ} \mathrm{C}$} \\
& (menit) & X1Y1 & X1Y2 & X2Y1 & X2Y2 & X0Y1 & X0Y2 \\
\hline 1 & 0 & 220 & 220 & 220 & 220 & 220 & 220 \\
2 & 10 & 200 & 180 & 210 & 190 & 180 & 180 \\
3 & 20 & 180 & 170 & 190 & 180 & 170 & 160 \\
4 & 30 & 170 & 160 & 180 & 160 & 160 & 140 \\
5 & 40 & 160 & 140 & 170 & 140 & 140 & 110 \\
6 & 50 & 145 & 120 & 160 & 120 & 120 & 100 \\
7 & 60 & 125 & 105 & 140 & 110 & 100 & 80 \\
8 & 70 & 110 & 90 & 125 & 95 & 85 & 70 \\
9 & 80 & 100 & 85 & 115 & 85 & 75 & 65 \\
10 & 90 & 90 & 75 & 105 & 80 & 70 & 60 \\
11 & 100 & 85 & 70 & 95 & 75 & 65 & 55 \\
12 & 110 & 75 & 65 & 85 & 70 & 55 & 50 \\
13 & 120 & 70 & 60 & 80 & 65 & 50 & 45 \\
14 & 150 & 65 & 55 & 70 & 60 & 45 & 40 \\
15 & 180 & 60 & 50 & 65 & 55 & 40 & 40 \\
16 & 210 & 55 & 45 & 60 & 50 & 40 & 40 \\
\hline
\end{tabular}

Penurunan suhu dalam ruang bakar tungku dapat dihitung dengan memperhatikan suhu awal setelah penggunaan tungku dan suhu akhir pada waktu yang ditetapkan. Hasil pengamatan pada Tabel 4 diatas dapat diketahui adanya penurunan suhu tersebut lebih tinggi pada tungku dengan model 4 lubang disebabkan suhu dalam ruang tungku lebih cepat merambat keluar dan karena hembusan udara dari luar lebih banyak. Demikian halnya dengan komposit bahan badan tungku, semakin banyak abu sekam padi yang digunakan maka panas atau suhu dalam ruang bakar tungku akan semakinlebih bertahan lama. Pengukuran suhu sampai pada 210 menit menunjukan suhu tertinggi dalam ruang tungku terdapat pada komposisi bahan dengan model 2 lubang (X2Y1) yakni sebesar $60{ }^{\circ} \mathrm{C}$ dan yang terendah pada tungku kontrol (tanpa menggunakan abu sekam) yaitu $40^{\circ} \mathrm{C}$.

\section{KESIMPULAN}

Hasil pengamatan dan uji fisik bendacoba komposit bahan tungku dengan bahan pengisi abu sekam padi menunjukkan susut kering terdapat pada kisaran 9,49 -5,24\% (A1-A5), Susut bakar rata-rata pada kisaran $1,82-0,80 \%$ dan kuat tekan 70,84-46,66 kg/ $\mathrm{cm}^{2}$. Hasil uji coba penggunaan tungku dengan memasak air diperoleh waktu tercepat adalah 11,65 menit dan penggunaan bahan bakar paling sedikit yakni $665 \mathrm{~g}$ terdapat pada tungku rumah tangga dengan komposit bahan 2 ASP + 3 TLP dengan model 2 lobang (X2Y1). Hasil pengamatan suhu dalam ruang tungku setelah penggunaan dalam tenggang waktu 210 menit menunjukkan bahwa suhu tertinggi terdapat pada tungku (X2Y1) sebesar $60^{\circ} \mathrm{C}$, dan yang terendah pada tungku (XOY1) dan (XOY2) yaitu 40 ${ }^{\circ} \mathrm{C}$. 


\section{DAFTAR PUSTAKA}

1. Christiawan, Darmanto S. Perlakuan bahan bata merah berserat abu sekam padi. Semarang: Universitas Diponegoro; 2010.

2. Tangendjaja B. Padi: Pemanfaatan limbah padi untuk pakan. Bogor: Pusat Penelitian dan Pengembangan Tanaman pakan; 1991.

3. Simanjuntak H dkk. Penelitian pemanfaatan abu sekam padi sebagai kebutuhan rumah tangga. Komunikasi No 126. Manado: Balai Penelitian Dan Pengembangan Industri Manado; 1993.

4. Harsono. Pembuatan silika amorf dan limbah sekam padi. J Ilmu Dasar Jur Fis FMIPA Univ Brawijaya. 2002;3.

5. Anonim. Rice Knowledge Bank [Internet]. International rice research institute. 2009 [cited 2012 Mar 24]. Available from: http://www.knowledgebank.irri.org/rkb/in dex/php/rice-milling/byproducts-andtheir-utilization/rice-husk.
6. Darmanto S, Murni dan Setyoko B. Analisa abu sekam padi sebagai bahankomposit mampu gesek. Laporan Penelitian Mandiri. Semarang: Fak. Teknik Universitas Diponegoro, Semarang; 2006.

7. Husnain. Mengenal silika sebagai unsur hara. Warta Penelitian dan Pengembangan Pertanian.; 2010.

8. Husni AA. Pemanfaatan limbah untuk bahan bangunan, pengembangan limbah pertambangan dan Industri untuk bahan bangunan. Bandung: , Pusat Penilitian dan Pengembangan Pemukiman; 2002.

9. Gultom O. Pengkajian recorveri energihasil proses insenerator untuk pemanasan udara pembakaran. Jakarta: Pusat Pengembangan Pengelolahan Limbah Radio Aktif; 2002.

10.Belonio AT. Rice Husk Gas Stove Handbook. Appropr Technol Center Dep Agric Eng Environ Manag Coll Agric Cent Philipp Univ Iloilo City, Philipp. 2005; 
